\title{
Radiofrequency Ablation-Associated Delayed Diaphragmatic Hernia Treated with the Thoracolaparotomy Approach: A Case Report
}

\author{
Hiroaki Yamane ${ }^{1}$, Toshihiko Kohashi'1,2 ${ }^{1}$ Ichiro Omori ${ }^{1}$, Akira Nakashima ${ }^{1}$, Eisuke Murakami ${ }^{3}$, \\ Koji Waki ${ }^{3}$, Hidenori Mukaida1, Naoki Hirabayashi' \\ ${ }^{1}$ Department of Gastroenterological Surgery, Hiroshima City Asa Citizens Hospital, Hiroshima, Japan \\ ${ }^{2}$ Department of Gastroenterological and Transplant Surgery, Applied Life Sciences, Institute of Biomedical and Health Sciences, \\ Hiroshima University, Hiroshima, Japan \\ ${ }^{3}$ Department of Gastroenterology, Hiroshima City Asa Citizens Hospital, Hiroshima, Japan \\ Email: tkohashi0303@gmail.com
}

How to cite this paper: Yamane, H., Kohashi, T., Omori, I., Nakashima, A., Murakami, E., Waki, K., Mukaida, H. and Hirabayashi, N. (2016) Radiofrequency AblationAssociated Delayed Diaphragmatic Hernia Treated with the Thoracolaparotomy Approach: A Case Report. Case Reports in Clinical Medicine, 5, 541-547.

http://dx.doi.org/10.4236/crcm.2016.512068

Received: November 29, 2016

Accepted: December 23, 2016

Published: December 26, 2016

Copyright $\odot 2016$ by authors and Scientific Research Publishing Inc. This work is licensed under the Creative Commons Attribution International License (CC BY 4.0).

http://creativecommons.org/licenses/by/4.0/

Open Access

\section{Abstract}

Background: Radiofrequency ablation (RFA) is an effective treatment for hepatocellular carcinoma (HCC). However, rare but serious complications may occur after RFA. We describe a case of diaphragmatic hernia associated with RFA. Case Presentation: A 68-year-old man with a history of hepatitis Crelated liver cirrhosis was admitted to our hospital because of lower abdominal pain. Three years earlier, he underwent RFA for HCC in segment 8. Computed tomography revealed that the intestine was intruding into the right thoracic cavity through a diaphragmatic hernia. On the basis of the diagnosis of right diaphragmatic hernia with a strangulated ileus, an emergency operation was performed. Perforation of the strangulated transverse colon into the right thoracic cavity was suspected, and a combined approach of laparotomy and thoracotomy was utilized. The operative findings showed that the diaphragmatic hernia was $3.5 \times 2.0 \mathrm{~cm}$ in diameter, and it was simply sutured with a nonabsorbable suture material. Resection of the intruded ischemic transverse colon was completed, and a covering ileostomy was performed. The patient was discharged without any complications. Conclusions: RFA is widely used for the treatment of HCC. Reports of early- and late-phase complications indicate that heat damage contributes to the fragility of neighboring organs. The occurrence of diaphragmatic hernia after RFA is one of the delayed complications. Although it rarely occurs, this complication requires emergency surgery. In conclusion, if perforation of the intestine into the thoracic cavity is suspected, thoracolaparotomy should be considered as a treatment option to 
prevent postoperative massive empyema.

\section{Keywords}

Diaphragmatic Hernia, Hepatocellular Carcinoma, Radiofrequency Ablation

\section{Introduction}

Hepatocellular carcinoma (HCC) is a common cancer and the third most frequent cause of cancer-related death [1]. Because of the advances in surgical techniques and perioperative management methods, liver resection can enhance the long-term survival of patients, with a 5-year overall survival rate of approximately 60\% [2] [3]. Radiofrequency ablation (RFA) is being increasingly used for the treatment of HCC because of its minimal invasiveness and positive longterm outcomes, which is equivalent to those of surgery in patients with ChildPugh class A and a tumor diameter of $<3 \mathrm{~cm} \mathrm{[4].}$

RFA therapy is considered a safer and less invasive intervention than hepatectomy [4]. However, it often causes complications such as intrahepatic abscess, bleeding, and biloma [5] [6]. RFA-related complications are subdivided into two categories: early- and late-phase complications. Direct organ injury is the main cause of early complications, and can lead to massive bleeding and perforation of the colon. Late-phase complications are difficult to precisely diagnose in the clinical setting. Diaphragmatic hernia has been reported as a rare late-phase complication. We report a case of delayed diaphragmatic hernia with a strangulated ileus after RFA for HCC, which was successfully treated with surgery.

\section{Case Presentation}

A 68-year-old man with a history of a duodenal ulcer and chronic cirrhosis caused by hepatitis $\mathrm{C}$ and recurrent HCC was admitted to our hospital for lower abdominal pain. He had previously undergone transcatheter arterial chemoembolization (TACE) and RFA for HCC in segments 8 and 4. He had received TACE treatment for recurrent HCC in segments 8 and 4 seven times in the last 36 months (Figure 1). On admission, he was afebrile and showed a normal consciousness level. His vital signs were unremarkable. The abnormal laboratory values obtained were as follows: total bilirubin, $2.4 \mathrm{mg} / \mathrm{dL}$ (reference, $0.4-0.8$ $\mathrm{mg} / \mathrm{dL}$ ); albumin, $3.0 \mathrm{mg} / \mathrm{dL}$ (reference, $3.9-4.5 \mathrm{mg} / \mathrm{dL}$ ); and prothrombin activity, $62 \%$ (reference, $70 \%-130 \%$ ). On the basis of laboratory data, the patient's disease was classified as Child-Pugh class B. A chest radiograph showed deviation of bowel gas across the right diaphragm. Computer tomography (CT) showed a dilated transverse colon that was intruding into the right thoracic space, with pleural effusion (Figure 2). These findings led to a preoperative diagnosis of diaphragmatic hernia with a strangulated ileus. Perforation of the transverse colon was strongly suspected, and an emergency operation with thoracolaparotomy was performed. The operative findings showed a right diaphragmatic hernia $(3.5 \times 2.0 \mathrm{~cm}$ in diameter), through which a large portion of the intestine 


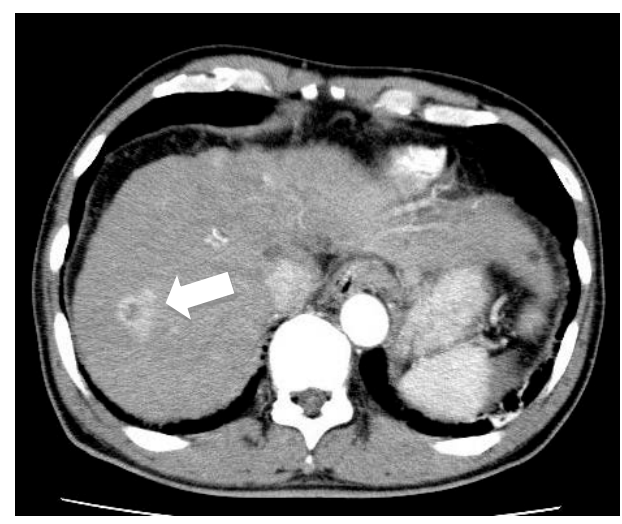

(a)

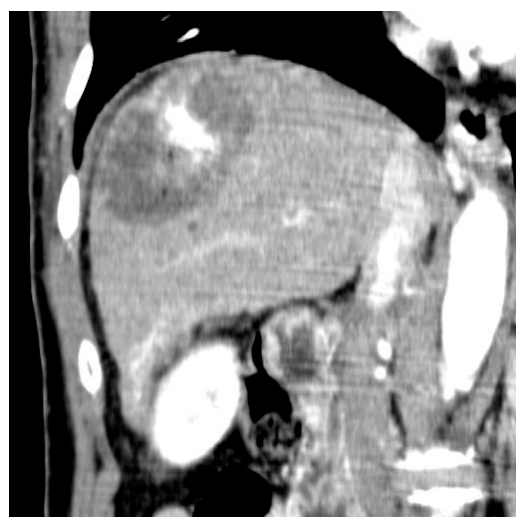

(b)

Figure 1. Previous computed tomography images. (a) Preoperative computed tomography image showing atrophy of the liver and the tumor in segment 8 before radiofrequency ablation (RFA) and transcatheter arterial chemoembolization (TACE) (white arrow); (b) Image showing the tumor and no evidence of injury to the diaphragm after RFA and TACE.

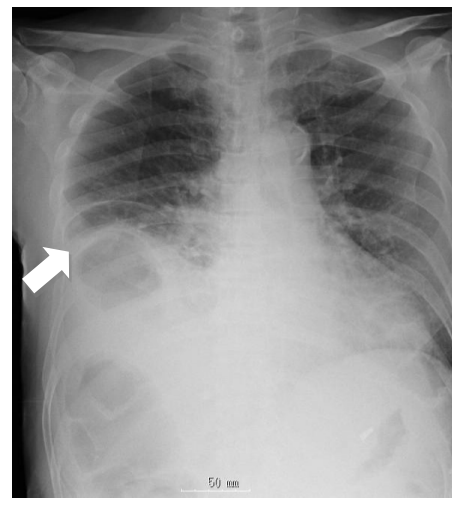

(a)

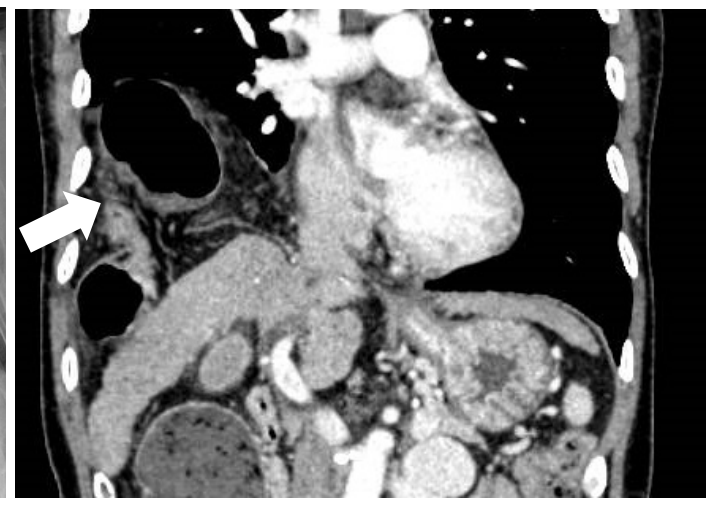

(b)

Figure 2. Preoperative images. (a) Chest radiograph showing transverse colonic gas in the right thoracic cavity (white arrow); (b) Computed tomography image taken on admission showing diaphragmatic herniation of the large intestine into the right thoracic cavity (white arrow).

was intruded and dilated (Figure 3). The hernia orifice was repaired with running suture of 3-0 Vicryl. After a colectomy, a covering ileostomy was performed. No postoperative complications developed, and the patient was discharged 24 days after the emergency surgery. He was continuously treated for recurrent HCC, and has showed no evidence of recurrent hernia during the 2-year follow-up period.

\section{Discussion}

RFA is an effective treatment option among several possible interventions for HCC. The incidence of complications after RFA has been reported to be approximately $2.4 \%$ - 9.5\% [5] [6] [7]. Rhim et al. [5] reported that the major complications after RFA were hepatic abscess, peritoneal hemorrhage, biloma, and 


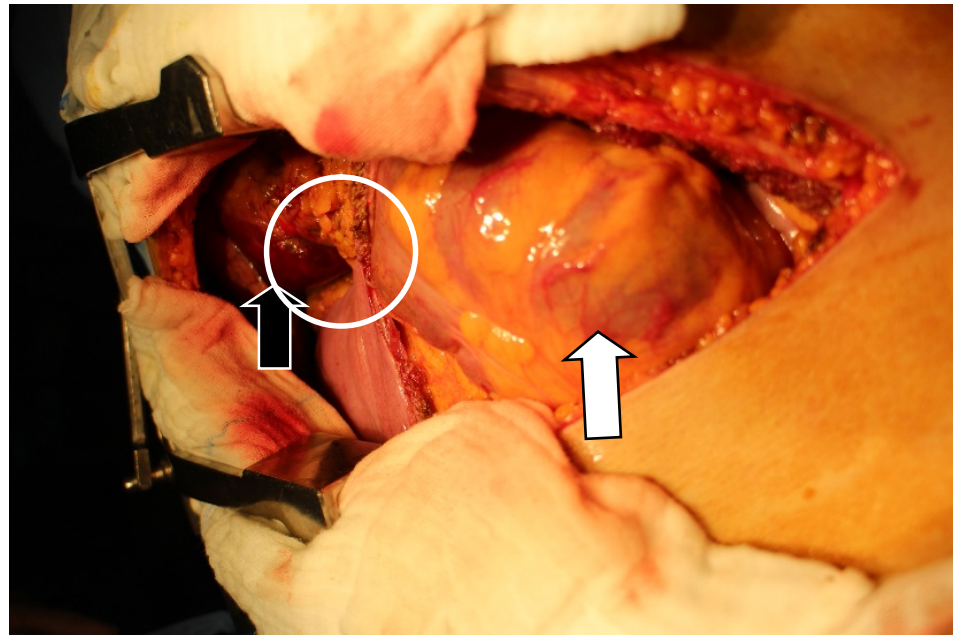

Figure 3. Perioperative picture. Photograph showing the transverse colon (black arrow) directly intruding into the right thoracic cavity through the diaphragmatic hernia (white circle). The white arrow shows the expanded ascending colon.

ground pad burn. Only 1 of the 1139 patients $(0.07 \%)$ they investigated had a diaphragmatic injury. In the study by Mulier et al. [6], diaphragmatic injuries occurred in 5 of 3670 patients $(0.001 \%)$. There was no description of late-phase diaphragmatic hernia in three studies [5] [6] [7]. However, in some reports, cases of late-phase diaphragmatic hernia required an emergency surgery because of a strangulated intestine [8] [10]-[18].

Diaphragmatic hernia after RFA seems to be caused by thermal damage to the diaphragm. The characteristic feature of a diaphragmatic hernia is its delayed onset after RFA. This delay occurs because the thermal damage induced by RFA causes a brittle point in the diaphragm. This brittle point weakens over time, resulting in the formation of a diaphragmatic hernia. The factors involved in the formation of a diaphragmatic hernia are delayed wound healing due to liver cirrhosis and increased abdominal pressure due to ascites [8]. To prevent thermal injury to organs during RFA, artificial ascites have been used to create a space between the liver and the skin or diaphragm [9]. Treatment of the primary disease such as hepatitis, to prevent progression to cirrhosis or hepatic atrophy, and control of ascites to decrease abdominal pressure are important to prevent the development of a diaphragmatic hernia.

We reviewed 13 case reports [8] [10]-[20] documenting the occurrence of diaphragmatic hernia after RFA for HCC, including our case. In the 13 cases, the diagnosis of diaphragmatic hernia after RFA was made after a mean period of 24.1 months (range, 7 - 96 months). The mean age of patients at diagnosis was 65.5 years (range, 46 - 81 years), and there were eight men and five women. The most common chief complaints were abdominal pain in nine patients $(69.2 \%)$ and dyspnea in seven patients (53.8\%). Five of the 13 patients (38.5\%) had right upper quadrant pain, and 2 patients including the present case patient (15.4\%) had lower abdominal pain. Among the 13 cases, surgical treatment was performed to repair the hernia in 11 cases including our case (Table 1) [8] [10]-[18]. 
Table 1. Summary of previously reported surgeries of diaphragmatic hernia afterradiofrequency ablation.

\begin{tabular}{|c|c|c|c|c|c|c|c|c|}
\hline Reference & $\begin{array}{c}\text { Age } \\
\text { (years) }\end{array}$ & Sex & $\mathrm{CP}$ class & $\begin{array}{c}\text { Onset of } \\
\text { defect }\end{array}$ & $\begin{array}{l}\text { Intestinal } \\
\text { resection }\end{array}$ & Approach & $\begin{array}{c}\text { Method of hernia } \\
\text { orifice closure }\end{array}$ & $\begin{array}{c}\text { Outcome(postoperative } \\
\text { hospital stay, days) }\end{array}$ \\
\hline Koda et al. [10] & 61 & $\mathrm{~F}$ & B & 13 & - & LT & Unknown & Dead \\
\hline Shibuya et al. [11] & 72 & M & Unknown & 18 & - & LT & Unknown & Alive (14) \\
\hline di Francesco et al. [12] & 50 & M & Unknown & 17 & - & LT & Simple sutures & Alive (8) \\
\hline Singh et al. [13] & 46 & $\mathrm{~F}$ & B & 19 & - & LS & Simple sutures & Alive (6) \\
\hline Boissier et al. [14] & 65 & $\mathrm{~F}$ & A & 7 & + & LT & Vicryl patch & Alive (27) \\
\hline Zhou et al. [8] & 61 & $\mathrm{~F}$ & Unknown & 12 & + & LT & Simple suture & Alive (60) \\
\hline Nakamura et al. [15] & 81 & M & A & 18 & + & LT & Simple sutures & Alive (15) \\
\hline Nomura et al. [16] & 62 & M & $\mathrm{C}$ & 96 & + & LS & Mesh repair & Alive (8) \\
\hline Saito et al. [17] & 81 & M & $\mathrm{C}$ & 33 & - & LT & Unknown & Dead \\
\hline Abe et al. [18] & 72 & $\mathrm{~F}$ & B & 15 & - & LT & Simplesutures & Alive \\
\hline Present case & 68 & M & B & 36 & + & LT, TT & Simple sutures & Alive (24) \\
\hline
\end{tabular}

CP class, Child-Pugh class; M, male; F, female; LS, laparoscopy; LT, laparotomy; TT, thoracotomy.

Two cases [19] [20] were followed with conservative management. The laparotomy approach was used in eight cases, and the thoracolaparotomy approach was performed in our case alone. We performed thoracolaparotomy because the preoperative findings raised the suspicion of both necrosis and perforation with a strangulated intestine. Moreover, it was difficult to pull the strangulated and expanded intestine out of the hernia orifice. In two recent cases [13] [16], the laparoscopic approach was performed to treat the diaphragmatic hernia. This method is less invasive for patients with a liver function disorder. Our patient recovered without complications and was discharged 24 days after the surgery. The length of hospital stay after surgery in our case was comparable to that in other reports (mean, 20.3 days; range, 6 - 60 days). The surgical methods for the hernia repair were as follows: simple ligation in six cases, Vicryl patch in one case, and mesh in one case. Nomura et al. [16] performed closure by using a mesh without intestinal resection. Concerning the surgical outcomes, no infectious complications occurred in patients with Vicryl patch and mesh.

\section{Conclusion}

We report a case of diaphragmatic hernia with a strangulated ileus after RFA. We suggest that thoracolaparotomy is an effective treatment approach for diaphragmatic hernia when perforation of a strangulated intestine into the thoracic cavity is suspected. Treatment of HCC with RFA must be performed carefully to prevent thermal injury to the diaphragm, and follow-up for HCC recurrence and complications is necessary.

\section{Acknowledgements}

This case report was not supported by any grants. 


\section{Competing Interests}

We have no financial or personal relationships with other people or organizations that could have influenced our work.

\section{Informed Consent}

Written informed consent was obtained from the patient for the publication of this case report.

\section{References}

[1] Ferlay, J., Shin, H.R., Bray, F., Forman, D., Mathers, C. and Parkin, D.M. (2010) Estimates of Worldwide Burden of Cancer in 2008: GLOBOCAN 2008. International Journal of Cancer, 127, 2893-2917. https://doi.org/10.1002/ijc.25516

[2] Kuroda, S., Tashiro, H., Kobayashi, T., Oshita, A., Amano, H. and Ohdan, H. (2012) No Impact of Perioperative Blood Transfusion on Recurrence of Hepatocellular Carcinoma after Hepatectomy. World Journal of Surgery, 36, 651-658. https://doi.org/10.1007/s00268-012-1425-3

[3] Fan, S.T., Mau Lo, C., Poon, R.T., Yeung, C., Leung Liu, C., Yuen, W.K., Ming, Lam, C., Ng, K.K. and Ching Chan, S. (2011) Continuous Improvement of Survival Outcomes of Resection of Hepatocellular Carcinoma: A 20-Year Experience. Annals of Surgery, 253, 745-758. https://doi.org/10.1097/SLA.0b013e3182111195

[4] Livraghi, T., Solbiati, L., Meloni, M.F., Gazelle, G.S., Halpern, E.F. and Goldberg, S.N. (2003) Treatment of Focal Liver Tumors with Percutaneous Radio-Frequency Ablation: Complications Encountered in a Multicenter Study. Radiology, 226, 441451. https://doi.org/10.1148/radiol.2262012198

[5] Rhim, H., Yoon, K.H., Lee, J.M., Cho, Y., Cho, J.S., Kim, S.H., Lee, W. J., Lim, H.K., Nam, G.J., Han, S.S., Kim, Y.H., Park, C.M., Kim, P.N. and Byun, J.Y. (2003) Major Complications after Radio-Frequency Thermal Ablation of Hepatic Tumors: Spectrum of Imaging Findings. Radiographics, 23, 123-134.

https://doi.org/10.1148/rg.231025054

[6] Mulier, S., Mulier, P., Ni, Y., Miao, Y., Dupas, B., Marchal, G., De Wever, I. and Michel, L. (2002) Complications of Radiofrequency Coagulation of Liver Tumours. British Journal of Surgery, 89, 1206-1222. https://doi.org/10.1046/j.1365-2168.2002.02168.x

[7] Curley, S.A., Marra, P., Beaty, K., Ellis, L.M., Vauthey, J.N., Abdalla, E.K., Scaife, C., Raut, C., Wolff, R., Choi, H., Loyer, E., Vallone, P., Fiore, F., Scordino, F., De Rosa, V., Orlando, R., Pignata, S., Daniele, B. and Izzo, F. (2004) Early and Late Complications after Radiofrequency Ablation of Malignant Liver Tumors in 608 Patients. Annals of Surgery, 239, 450-458. https://doi.org/10.1097/01.sla.0000118373.31781.f2

[8] Zhou, M., He, H., Cai, H., Chen, H., Hu, Y., Shu, Z. and Deng, Y. (2013) Diaphragmatic Perforation with Colonic Herniation Due to Hepatic Radiofrequency Ablation: A Case Report and Review of the Literature. Oncology Letters, 6, 1719-1722.

[9] Uehara, T., Hirooka, M., Ishida, K., Hiraoka, A., Kumagi, T., Kisaka, Y., Hiasa, Y. and Onji, M. (2007) Percutaneous Ultrasound-Guided Radiofrequency Ablation of Hepatocellular Carcinoma with Artificially Induced Pleural Effusion and Ascites. Journal of Gastroenterology, 42, 306-311. https://doi.org/10.1007/s00535-006-1949-0 
[10] Koda, M., Ueki, M., Maeda, N. and Murawaki, Y. (2003) Diaphragmatic Perforation and Hernia after Hepatic Radiofrequency Ablation. American Journal of Roentgenology, 180, 1561-1562. https://doi.org/10.2214/ajr.180.6.1801561

[11] Shibuya, A., Nakazawa, T., Saigenji, K., Furuta, K. and Matsunaga, K. (2006) Diaphragmatic Hernia after Radiofrequency Ablation Therapy for Hepatocellular Carcinoma. American Journal of Roentgenology, 186, S241-S243. https://doi.org/10.2214/AJR.04.0931

[12] di Francesco, F., di Sandro, S., Doria, C., Ramirez, C., Iaria, M., Navarro, V., Silvestry, S., Needleman, L. and Frank, A. (2008) Diaphragmatic Hernia Occurring 15 Months after Percutaneous Radiofrequency Ablation of a Hepatocellular Cancer. The American Surgeon, 74, 129-132.

[13] Singh, M., Singh, G., Pandey, A., Cha, C.H. and Kulkarni, S. (2011) Laparoscopic Repair of Iatrogenic Diaphragmatic Hernia Following Radiofrequency Ablation for Hepatocellular Carcinoma. Hepatology Research: The Official Journal of the Japan Society of Hepatology, 41, 1132-1136. https://doi.org/10.1111/j.1872-034X.2011.00865.x

[14] Boissier, F., Labbe, V., Marchetti, G., Valade, S. and Djibre, M. (2011) Acute Respiratory Distress and Shock Secondary to Complicated Diaphragmatic Hernia. Intensive Care Medicine, 37, 725-726. https://doi.org/10.1007/s00134-011-2142-3

[15] Nakamura, T., Masuda, K., Thethi, R.S., Sako, H., Yoh, T., Nakao, T. and Yoshimura, N. (2014) Successful Surgical Rescue of Delayed Onset Diaphragmatic Hernia Following Radiofrequency Ablation for Hepatocellular Carcinoma. Ulusal Travma ve Acil Cerrahi Dergisi, 20, 295-299. https://doi.org/10.5505/tjtes.2014.03295

[16] Nomura, R., Tokumura, H. and Furihata, M. (2014) Laparoscopic Repair of a Diaphragmatic Hernia Associated with Radiofrequency Ablation for Hepatocellular Carcinoma: Lessons from a Case and the Review of the Literature. International Surgery, 99, 384-390. https://doi.org/10.9738/INTSURG-D-14-00025.1

[17] Saito, T., Chiba, T., Ogasawara, S., Inoue, M., Wakamatsu, T., Motoyama, T., Kanogawa, N., Suzuki, E., Ooka, Y., Tawada, A., Matsubara, H. and Yokosuka, O. (2015) Fatal Diaphragmatic Hernia Following Radiofrequency Ablation for Hepatocellular Carcinoma: A Case Report and Literature Review. Case Reports in Oncology, 8, 238-245. https://doi.org/10.1159/000431310

[18] Abe, T., Amano, H., Takechi, H., Fujikuni, N., Sasada, T., Yoshida, M., Yamaki, M., Nakahara, M. and Noriyuki, T. (2016) Late-Onset Diaphragmatic Hernia after Percutaneous Radiofrequency Ablation of Hepatocellular Carcinoma: A Case Study. Surgical Case Reports, 2, 25. https://doi.org/10.1186/s40792-016-0148-3

[19] Yamagami, T., Yoshimatsu, R., Matsushima, S., Tanaka, O., Miura, H. and Nishimura, T. (2011) Diaphragmatic Hernia after Radiofrequency Ablation for Hepatocellular Carcinoma. Cardiovascular and Intervention Radiology, 34, S175-S177. https://doi.org/10.1007/s00270-010-9832-Z

[20] Kim, J.S., Kim, H.S., Myung, D.S., Lee, G.H., Park, K.J., Cho, S.B., Joo, Y.E. and Choi, S.K. (2013) A Case of Diaphragmatic Hernia Induced by Radiofrequency Ablation for Hepatocellular Carcinoma. Korean Journal of Gastroenterology, 62, 174178. https://doi.org/10.4166/kjg.2013.62.3.174 
Submit or recommend next manuscript to SCIRP and we will provide best service for you:

Accepting pre-submission inquiries through Email, Facebook, LinkedIn, Twitter, etc. A wide selection of journals (inclusive of 9 subjects, more than 200 journals)

Providing 24-hour high-quality service

User-friendly online submission system

Fair and swift peer-review system

Efficient typesetting and proofreading procedure

Display of the result of downloads and visits, as well as the number of cited articles Maximum dissemination of your research work

Submit your manuscript at: http://papersubmission.scirp.org/

Or contact crcm@scirp.org 